\title{
Analysis of Burnout Indices and Components of Organizational Climate among Female Factory Workers
}

\author{
Jinky Leilanie Lu, MOH, PhD \\ National Institutes of Health, University of the Philippines Manila
}

\begin{abstract}
Introduction. With the growing number of females employed as factory workers, it is important to look into the phenomenon of burnout and related organizational climate affecting these workers.
\end{abstract}

Objectives. The study's objectives were: 1) to come up with the indices of burnout among Filipino female factory workers and; 2) to come up with indices of organizational climate components of job autonomy, the content of the job, and nature of management through exploratory factor analysis.

Methods. The secondary data used for this study were from a cross-sectional study involving 344 female factory workers. The indicators of the organizational climate were derived through exploratory factor analysis of items in the dataset. Exploratory Factor Analysis was used to reduce the variables into a fewer set of "Component Variables." The technique explored the relationship of each indicator and then grouped them according to which component they were highly correlated. Using the factor loadings as weights, the index score was generated. The organizational climate indices were derived from the factor loading scores. Burnout Score was derived from respondents' answers on nine items relating to burnout. The organizational climate indexes were also generated using factor analysis with these components- job autonomy, content of the job, and nature of management. Cronbach alpha was generated for all the items under each index to show the internal consistency and scale reliability.

Results. There were 344 female respondents with a mean age of 26 (SD=5.02), and the majority were single (69.21\%). Nine items were measured with the lowest average response "work is boring" (0.259 \pm .560$)$ for burnout indices. The highest mean answer for the item "work requires new skills or upskilling regularly" at $1.619 \pm .762$, suggesting that most respondents were required to upskill regularly. "Salary is not enough to meet worker's needs" also has a high average response, suggesting that most respondents felt that their salary was insufficient to sustain their daily needs. The total burnout score indicates that workers experienced moderate burnout. The indices for burnout have good internal consistency and scale reliability (Cronbach alpha $=0.712$ ). The organizational climate was grouped into Indexes through factor analysis, namely, Autonomy on Quality Index, Autonomy on Rest Index, Skilled work content Index, Physical work content Index, Hazardous work content Index, Health, Safety, and Compensation Index, and Training Index. Autonomy on Quality Index has a mean of $66.877 \pm 31.934$, suggesting that the autonomy on quality for respondents was moderately high, while Autonomy on Rest Index was $24.159 \pm 30.788$, suggesting that respondents have low autonomy on rest. The skilled work content index was high at an average of $70.801 \pm 22.87$, while physical work content and hazardous work content index were low at 29.398 and 25.377, respectively. Health, Safety, and Compensation index average was very low at 8.891 \pm 8.524 .

Conclusion. This study came up with indices of burnout unique to female factory workers. The indexes were boredom/ boring work, repetitious tasks, fast-paced work, work pressure, not sufficient compensation, work-home conflicts, upskilling, physically tiring, mentally tiring, and salary is not sufficient to meet basic needs. This study also came up with the indexes of organizational climate relating to job autonomy, content of job, and nature of management. The several items under each of these components were subjected to Factor Analysis to come up with indexes of organizational climate. Thus, the contribution of this study is coming up with a burnout index unique to the Filipino

Corresponding author: Jinky Leilanie Lu, $\mathrm{MOH}, \mathrm{PhD}$ National Institutes of Health

University of the Philippines Manila

623 Pedro Gil Street, Ermita, Manila 1000, Philippines

Email: jinky_lu@yahoo.com factory worker, not just based on subjective expert opinion, but data-driven and statistically derived.

Key Words: burnout, female factory workers, organizational climate, job autonomy, nature of management 


\section{INTRODUCTION}

Work is an essential aspect of an individual's life as it affects the quality of living. In the Philippines, an increase in economic growth was observed, which produces a growing number of employment and business opportunities. ${ }^{1}$ This phenomenon brought about an increase in work demands among the workforce, significantly impacting women's work. These workers from manufacturing were reported to usually experience stress, a longer period of work hours, low compensation, and poor work-life balance..$^{2-5}$

A study in the Philippines claimed that gender plays a vital role in workplace stress that causes burnout with the increasing number of female laborers in the workforce in some countries in Asia. ${ }^{6}$ In China, women are high in number in labor-intensive manufacturing industries such as toys, garments, and electronics. ${ }^{7}$ While Bangladesh's readymade garment export-manufacturing sector has higher female laborers in a factory set-up. ${ }^{5,8}$ For both studies, the female factory worker has been under labor-intensive work, which caused an imbalance in work and life, leading to more physical and psychological problems, which may cause burnout. In addition, numerous studies found that women in the labor force usually experience more stressors such as discrimination, stereotyping, marriage or work interface, social isolation, sexual harassment, and demand of household duties which increased the amount of stress leading to burnout. ${ }^{3-6}$

The organizational climate was found to contribute to aiding employees' satisfaction or dissatisfaction at the workplace, which played a role in aggravation or prevention of burnout. For instance, the dominance of males in managerial and leadership positions puts female workers at a disadvantage as they have less power and voice in such a set-up. ${ }^{5}$ Moreover, workplace violence that often took place in the garment sector was likely to lower the life satisfaction of female workers, which increased the likelihood of experiencing burnout. ${ }^{8}$

In related literature, organizational climate is a set of policies, practices, and procedures in a multi-dimensional work organization such as autonomy, authority, structure, and leadership style. ${ }^{9}$ This study on female factory workers referenced the dimensions of organizational climate from this definition. Also, in another study, burnout syndrome was dependent on the organizational climate. Differences in the level of burnout were observable depending on the different types of organizational climate. ${ }^{10}$

The World Health Organization also categorized burnout as an "occupational phenomenon" and is defined as the result of "chronic workplace stress" that is not managed well. ${ }^{11}$ The phenomenon of burnout related to work-related stress, fatigue, and exhaustion has been the research point, such as the review by Heinemann \& Heinemann, 2017 on burnout spanning 40 years. ${ }^{12}$

In this study of female factory workers, the burnout indices were constructed from various literature reviews.
In the study, workload perceptions and human resource management practices were identified as factors relating to stress. ${ }^{13}$ The workload was measured using dimensions of mental demand, physical demand, training and employee development, and compensation and benefit. On the other hand, burnout was measured using physical exhaustion, mental exhaustion, and reduced personal accomplishment. In reference to the study of Herminingsih and Kurniasih (2018), some indices identified in this study of female factory workers included workload, mentally demanding work, physically demanding work, provision of training as well as compensation. ${ }^{13}$

The study's objectives were: 1) to come up with the indices of burnout among Filipino female factory workers and; 2) to come up with indices of organizational climate components of job autonomy, content of the job, and nature of management through exploratory factor analysis. Thus, this study can be a basis for further investigation of work burnout and its associated risk factor.

\section{MATERIALS AND METHOD}

The secondary data used for this study were from a cross- sectional study involving 344 female factory workers. The respondents were sampled from multiple identified factories, and the information obtained was gathered through self-administered questionnaires. The researcher "mined" the databases for helpful information using statistical and other computational techniques to look for patterns. Unlike traditional methods where a researcher starts generating a hypothesis, the Big Data approach started by harvesting and storing data, then looked for patterns. ${ }^{14}$

The number of subjects involved in the study was determined through a random sample of females working in identified factories. The sample size was computed using Daniel's Formula for sample size computation, $\mathrm{n}$ $\left.=\left(Z_{\alpha / 2}\right)^{2} p(1-p)\right) / d^{2}$, where $Z_{\alpha / 2}$ is the critical value of the normal distribution, $\alpha$ is the confidence level, $p$ is the sample proportion, and $\mathrm{d}$ is the margin of error. Assuming a design effect of 1 , confidence level at $95 \%$, setting the margin of error at $5 \%$, and setting the sample proportion at $50 \%$ to maximize the sample size, the final sample size was 384. However, the number of factory workers included in the analysis is only 344 because some responses needed to be dropped due to contamination, such as non-response and no gender/sex information.

The analysis was conducted on a wide range of sociodemographic, health, and occupational data collected on 344 female factory workers. Socio-demographic data collected were age, sex, monthly salary, civil status, educational attainment, and employment data. In addition, sociodemographic data were identified for the descriptive analysis of the population studied. Health data gathered were selfreported frequency of various mental health symptoms, physical health symptoms, and injuries. Employment data 
collected were workload, shift schedule, work schedule, physical exertion, job satisfaction, seminars on occupational health, and exposure to occupational hazards and chemicals at work.

Organizational Climate Factors were gathered from the respondents. The organizational climate factors were grouped into Job Autonomy, Content of the Job, Nature of Management, and Hazard Exposures. Items under Job Autonomy were scored as a 3-point Likert scale where 0 is "no," 1 is "sometimes," 2 is "yes." In contrast, items under the Content of the Job, Nature of Management, and Hazard Exposures are dichotomous variables where 0 is "no," and 1 is "yes."

Burnout Score was derived from respondents' answers to 9 questions relating to burnout. The relationships of other organizational climate factors can be explored further with the burnout score developed here as the endogenous variable and the organizational climate indices as the exogenous variables. This can be pursued as a sequel to this paper.

The indicators of the organizational climate were derived through exploratory factor analysis of items in the dataset. Exploratory Factor Analysis is a technique to reduce the variables into a fewer set of "Component Variables." The method explored the relationship of each indicator and then grouped them according to which component they were highly correlated. The component then summarized the information contained by the indicators whose factor loadings were highly correlated to it. The organizational climate indices were derived from the factor loading scores. (Figure 1)

After the Exploratory Factor Analysis, the factor scores were obtained for each of the components. These scores were then normalized using the formula:

$$
z_{i}=100\left(\frac{x_{i}-\min (x)}{\max (x)-\min (x)}\right)
$$

This equation will scale the scores, which was initially normally distributed with a mean of 0 and variance 1 , to a scale from 0 to 100 , where 0 is given if the answer "no" was given for all numbers and 100 if "yes" was given for all items. The purpose of this was to create interpretability to the derived index scores since interpretability was difficult for the

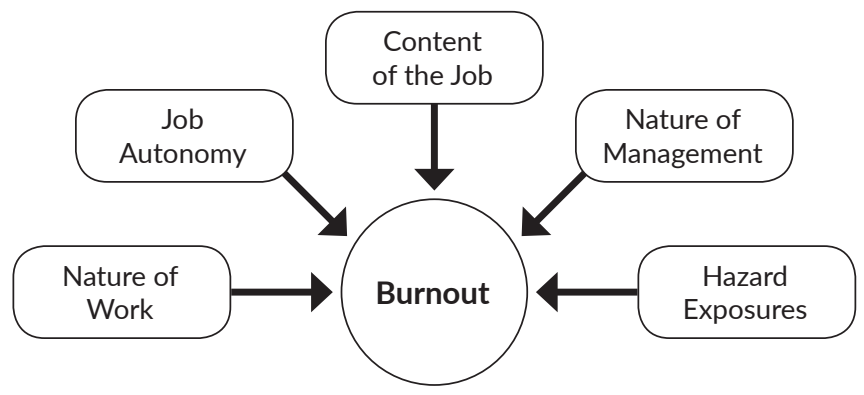

Figure 1. The Framework of Relationships of Burnout and Organizational Indices. original factor scores. K-Means Cluster analysis was done to create three classifications for the scores to determine where to start a cutoff for "low," "moderate," and "high" index scores.

To ensure the dataset's quality, it was cleaned for possible contamination through outlier detection, detection of encoding errors and duplicates, and exclusion of respondents outside the scope, such as supervisory employees. More specific questions or information were also not contained in the dataset. The same limitations also limit the study as the primary source, such as missing data and non-response to sensitive questions.

This study sought registration with the UP Manila Research Grants Administration Office (RGAO). Ethics and informed consent were secured. This guaranteed that researchers involved in the study followed ethical research practices and ensured the confidentiality of respondents whose data were included in the study.

\section{RESULTS}

For socio-demographic data, the age of the respondents ranged from 18 to 47 . The majority belonged to the 20-24 and the 25-29 age bracket, together consisting of $76.7 \%$ of the respondents. The mean age was $26(\mathrm{SD}=5.02) .69 .21 \%$ were single, while $28.74 \%$ were married. Most respondents did not have a baccalaureate degree for educational attainment, with a cumulative share of $61.76 \%$. The median length of current employment was 29 months, while the median length of work including previous employment was 36 months. The majority have an 11- to 30-minute travel time to work at $40.12 \%$, followed by 31 minutes to 1 hour at $30.09 \%$.

Nine items measured with the lowest average response "work is boring" $(0.259 \pm .560)$ for burnout indices. The highest mean answer was for the item "work requires new skills or upskilling regularly" at $1.619 \pm .762$, suggesting that most respondents were required to upskill regularly. "Salary is not enough to meet worker's needs" also has a high average response, meaning that most respondents felt that their salary was insufficient to sustain their daily needs. The "Burnout Score" is the sum of the score from the questions for "Nature of Task." There were nine questions, where burnout score had a minimum score of 0 and a maximum score of 18 . The average burnout score among the respondents was 9.09, which meant that many workers experienced burnout, with a standard deviation of 3.9.

K-Means Cluster analysis was also done to create three classifications for the scores of burnouts to determine where to start a cutoff for "low," "moderate," and "high" index scores. The result of the cluster analysis is shown in Appendix 1.

The result of the cluster analysis of burnout scores shows that 0 to 5 can be classified as "low burnout," 6 to 10 can be classified as "moderate burnout," while 11 and above can be classified as "high burnout."

Generally, the workers experienced a moderate burnout score. (Table 1) The indices for burnout were tested for 
internal consistency and scale reliability. The Cronbach alpha was 0.712 , which was a good measure. (Table 2)

The P-P plot for the regression model residuals for burnout does not deviate much from the normal line. The slight deviations from the normal line can be due to the limited number of unique observations on the dependent variable. (Appendix 2) The residual scatterplot is scattered without any discernable pattern. This implies that there was no problem with regard to heteroskedasticity.

Components of organizational climate were grouped into three categories: job autonomy, the content of the job, and the nature of management. There were five items included for Job Autonomy. The lowest average response was for "worker may decide to slow down his/her pace" $(0.37 \pm .724)$, suggesting that most respondents did not have autonomy over the pace. (Table 3) There were seven items for Content of the Job. The indicators for "Content of the Job" were measured using proportion. $86.92 \%$ of the respondents reported that their work required much knowledge and skill, while $77.33 \%$ of the respondents have work that required mental concentration. On the other hand, $13.37 \%$ reported that their work required awkward positions while working, while $19.19 \%$ reported that their work required a heavy physical load (Table 3). Finally, there were nine items for Nature of Management measured as proportion. 86.63\% of the respondents reported that there was a Health and Safety policy posted at the workplace. $85.17 \%$ reported

Table 1. Mean for Burnout Indices among Female Factory Workers

\begin{tabular}{lcc}
\hline \multicolumn{1}{c}{ Indices of Burnout } & Mean & SD \\
Work is boring & 0.2598 & 0.5605 \\
\hline Work is repetitious & 1.3172 & 0.8905 \\
\hline Work requires fast pacing & 1.0846 & 0.9172 \\
\hline Work produces pressure on the part of the worker & 1.1450 & 0.9294 \\
\hline Work is too much and not proportional to salary & 0.6526 & 0.8617 \\
\hline $\begin{array}{l}\text { Worker encounters conflict of priorities between } \\
\text { work and family }\end{array}$ & 0.7039 & 0.8581 \\
\hline Work requires upskilling regularly & 1.6193 & 0.7628 \\
\hline Work is physically and mentally tiring & 0.9668 & 0.8887 \\
\hline Salary is not enough to meet worker's needs & 1.4139 & 0.8317 \\
\hline Burnout Score & 9.0900 & 3.9840 \\
\hline
\end{tabular}

Table 2. Cronbach Alpha of Indices of Burnout

\begin{tabular}{lc}
\multicolumn{1}{c}{ Indices of Burnout } & Cronbach's Alpha \\
Work is boring & 0.712 \\
$\begin{array}{ll}\text { Work is too much and not proportional to salary } \\
\text { Worker encounters conflict of priorities between } \\
\text { work and family }\end{array}$ \\
$\begin{array}{ll}\text { Work is physically and mentally tiring } \\
\text { Work requires fast pacing }\end{array}$ \\
\hline Work produces pressure on the part of the worker \\
\hline Work requires upskilling regularly
\end{tabular}

that workers were entitled to compensations/benefits given by the company. On the other hand, only $59.01 \%$ reported that their company holds programs and training to develop workers' skills, while only $53.20 \%$ reported participating in said programs and training. (Table 3 )

The hazard exposure present in the work environment was also measured. The highest proportions were observed for the following items: exposed to high temperatures in the workplace $(0.8939 \pm 0.7661)$, exposed to intoxicating odors $(0.7796 \pm 0.8733)$, and standing for hours during his/her work shift $(0.7469 \pm 0.9015)$. Conversely, the lowest means were observed for the following: exposed to vapors $(0.2898$ $\pm 0.6666)$, exposed to fumes $(0.3878 \pm 0.7076)$, and exposed to dust $(0.4367 \pm 0.7689)$. (Table 4$)$

\section{Exploratory Factor Analysis}

Exploratory Factor Analysis is a technique to reduce the variables into a fewer set of component variables. The method explores the relationship of each indicator and then groups them according to which component they are highly correlated with.

The analysis was done on each of the groups of questions. In addition, Scale Reliability analysis using Cronbach's Alpha was used to improve and assess the internal consistency of the retained items.

For Job Autonomy, scale reliability analysis showed no significant increase in the Cronbach's Alpha score for items dropped; hence all items were retained. EFA showed two components with eigenvalues greater than 1 , combined explaining up to $65.296 \%$ of the variance from the five items analyzed. "Worker may decide how he/she would finish work," "Worker may decide how fast he/she'd work," and "Worker may decide how much he/she'd accomplish" were highly correlated to the first component, with the latent label as "Autonomy on Quality." "Worker may take rest breaks aside from scheduled rest breaks" and "Worker may take rest breaks aside from scheduled rest breaks" were correlated to the second component with a latent label as "Autonomy on Rest." (Table 3)

The same methodology was done for Content of the Job items. There was also no significant increase in the Cronbach's Alpha score after dropping some items; hence all items were retained. EFA revealed three components with eigenvalues greater than 1 , combined explaining up to $59.554 \%$ of the total variance of the seven items. "Work requires much knowledge and skill," "Work requires strict visual inspection," and "Work requires severe concentration" were grouped into the first component with a latent labeled as "Skilled work content component." "Work requires heavy physical load" and "Work requires awkward positions while working" were grouped into the second component with a latent labeled as "Physical work content component." Finally, "Work involves handling chemicals" and "Work involves exposure to radiation" were grouped into the third component with a latent labeled as "Hazardous work content." (Table 3) 
Table 3. Mean, Proportion and Factor Analysis of the Organizational Climate Indices for Job Autonomy, Content of Job, and Nature of Management

Items

\begin{tabular}{|c|c|c|c|c|c|}
\hline Items & Mean & SD & Component & $\begin{array}{c}\text { Variance } \\
\text { Explained (\%) }\end{array}$ & $\begin{array}{l}\text { Cronbach's } \\
\text { Alpha }\end{array}$ \\
\hline \multicolumn{6}{|l|}{ Job Autonomy } \\
\hline Worker may decide how he/she would finish work & 1.510 & 0.809 & \multirow{3}{*}{$\begin{array}{l}\text { Autonomy } \\
\text { on Quality }\end{array}$} & \multirow[t]{3}{*}{36.918} & \multirow[t]{5}{*}{0.592} \\
\hline Worker may decide how fast he/she'd work & 1.310 & 0.899 & & & \\
\hline Worker may decide how much he/she'd accomplish & 1.200 & 0.921 & & & \\
\hline Worker may take rest breaks aside from scheduled rest breaks & 0.580 & 0.838 & \multirow{2}{*}{$\begin{array}{l}\text { Autonomy } \\
\text { on Rest }\end{array}$} & \multirow[t]{2}{*}{28.378} & \\
\hline Worker may decide to slow down his/her pace & 0.370 & 0.724 & & & \\
\hline \multicolumn{6}{|l|}{ Content of the Job } \\
\hline Work requires much knowledge and skill & 0.869 & 0.338 & \multirow{3}{*}{$\begin{array}{l}\text { Skilled work } \\
\text { content }\end{array}$} & \multirow[t]{3}{*}{21.220} & \multirow[t]{7}{*}{0.413} \\
\hline Work requires strict visual inspection & 0.433 & 0.496 & & & \\
\hline Work requires severe mental concentration & 0.773 & 0.419 & & & \\
\hline Work requires heavy physical load & 0.192 & 0.394 & \multirow{2}{*}{$\begin{array}{l}\text { Physical work } \\
\text { content }\end{array}$} & \multirow[t]{2}{*}{20.565} & \\
\hline Work requires awkward positions while working & 0.134 & 0.341 & & & \\
\hline Work involves handling chemicals & 0.215 & 0.412 & \multirow{2}{*}{$\begin{array}{c}\text { Hazardous } \\
\text { work content }\end{array}$} & \multirow[t]{2}{*}{17.769} & \\
\hline Work involves exposure to radiation & 0.241 & 0.429 & & & \\
\hline \multicolumn{6}{|l|}{ Nature of Management } \\
\hline Health and Safety policy posted at the workplace & 0.866 & 0.341 & \multirow{7}{*}{$\begin{array}{c}\text { Health, } \\
\text { Safety, and } \\
\text { Compensation }\end{array}$} & \multirow[t]{7}{*}{42.988} & \multirow[t]{9}{*}{0.735} \\
\hline Company gives seminars on healthy and safe living & 0.733 & 0.443 & & & \\
\hline Worker participate in seminars held by his/her employer & 0.625 & 0.485 & & & \\
\hline Workers are entitled to compensations/benefits given by the company & 0.852 & 0.356 & & & \\
\hline Company has policies covering giving promotions and training to workers & 0.590 & 0.493 & & & \\
\hline Worker is entitled to insurance for accidents happening in the workplace & 0.532 & 0.500 & & & \\
\hline Company has policies against harassment and discrimination among workers & 0.724 & 0.448 & & & \\
\hline Company holds programs and training to develop skills of workers & 0.642 & 0.480 & \multirow{2}{*}{$\begin{array}{l}\text { Upskilling } \\
\text { and Training }\end{array}$} & \multirow[t]{2}{*}{16.417} & \\
\hline Worker participates in programs and training held by his/her employer & 0.648 & 0.478 & & & \\
\hline
\end{tabular}

Finally, for Nature of Management, the Cronbach's Alpha score was .735 , which already has good internal consistency; hence all items were retained. Two components with an eigenvalue greater than 1 were revealed during the EFA, explaining up to $59.404 \%$ of the variance of the nine

Table 4. The proportion of Hazard Exposure for Female Factory Workers

\begin{tabular}{|c|c|c|}
\hline Hazard Exposure & Proportion & SD \\
\hline Exposure to dust in the workplace & 0.4367 & 0.7689 \\
\hline Exposure to fumes in the workplace & 0.3878 & 0.7076 \\
\hline $\begin{array}{l}\text { Exposure to intoxicating odors in the } \\
\text { workplace }\end{array}$ & 0.7796 & 0.8733 \\
\hline Exposure to vapors in the workplace & 0.2898 & 0.6666 \\
\hline $\begin{array}{l}\text { Exposure to cold temperatures in the } \\
\text { workplace }\end{array}$ & 0.6286 & 0.7661 \\
\hline $\begin{array}{l}\text { Exposure to high temperatures in the } \\
\text { workplace }\end{array}$ & 0.8939 & 0.8571 \\
\hline Exposure to excessive noise in the workplace & 0.6327 & 0.8467 \\
\hline Exposure to radiation in the workplace & 0.6490 & 0.9004 \\
\hline $\begin{array}{l}\text { Worker is required to stand for hours during } \\
\text { his/her work shift }\end{array}$ & 0.7469 & 0.9015 \\
\hline
\end{tabular}

items. The items "Health and Safety policy posted at the workplace," "Company gives seminars on healthy and safe living," "Worker participates in seminars held by his/her employer," "Workers are entitled to compensations/benefits given by the company," "Company has policies covering giving promotions and training to workers," "Worker is entitled to an insurance for accidents happening in the workplace," and "Company has policies against harassment and discrimination among workers" were grouped into the first component with a latent labeled as "Health, Safety, and Compensation." On the other hand, "Company holds programs and training to develop skills of workers" and "Worker participates in programs and training held by his/ her employer" were grouped into the second component with a latent labeled as "Training programs." (Table 3)

After the Exploratory Factor Analysis, the factor scores were obtained for each of the components. These scores were then normalized using the formula below. This equation scales the scores. This scoring served as the Organizational Climate Indices.

$$
z_{i}=100\left(\frac{x_{i}-\min (x)}{\max (x)-\min (x)}\right)
$$


Table 5. Mean of Organizational Climate Indices after Factor Analysis

\begin{tabular}{lccc} 
& Mean & Std. Deviation & N \\
\hline Autonomy on Quality Index & 66.877 & 31.934 & 337 \\
\hline Autonomy on Rest Index & 24.159 & 30.788 & 337 \\
\hline Skilled work content Index & 70.801 & 22.870 & 344 \\
\hline Physical work content Index & 29.398 & 25.251 & 344 \\
\hline Hazardous work content Index & 25.377 & 25.019 & 344 \\
\hline $\begin{array}{l}\text { Health, Safety, and Compensation } \\
\text { Index }\end{array}$ & 8.891 & 8.524 & 344 \\
\hline Training Index & 29.582 & 12.632 & 344 \\
\hline
\end{tabular}

Table 5 shows the distribution of each index. Autonomy on Quality Index has a mean of $66.877 \pm 31.934$, suggesting that the autonomy on quality for respondents was moderately high, while Autonomy on Rest Index was $24.159 \pm 30.788$, suggesting that respondents have low autonomy on rest. The skilled work content index was high at an average of 70.801 \pm 22.87 , while physical work content and hazardous work content indexes were low at 29.398 and 25.377, respectively. Finally, Health, Safety, and Compensation index average was very low at $8.891 \pm 8.524$.

\section{DISCUSSION}

The relationship between burnout, job demands, job resources, and work engagement was looked into in a study. ${ }^{15}$ The variables included workload, cognitive demands, time pressure, work requiring continuous attention, autonomy in planning own work," and "work requires learning new things." In this study among female factory workers, similar indices were used for the organizational climate index, namely, job autonomy, content of job, and nature of management. The items included in each of these three components yielded a high Cronbach alpha, which showed high internal consistency and high scale reliability of the several items used for constructing the indices for burnout and organizational climate.

Furthermore, Gauche, de Beer, and Brink (2017) explored employees' perceptions of demands identified as being at risk of burnout. ${ }^{16}$ These were job demands, life demands, and health concerns. For job demands, the identified subthemes were cognitive demands, emotional demands, job dissatisfaction, job expectations, job insecurity, remuneration, work overload, among others. This study also used these variables among female factory workers and tested them through exploratory factor analysis to objectively categorize individual items into major indices. In this way, indices of burnout and organizational climate were constructed not from mere subjective expert opinion but were data-driven and derived from statistical analysis.

In this study among female factory workers, the respondents frequently reported that their work was repetitious $(1.3172 \pm 0.8905)$, required fast pacing (1.0846 $\pm 0.9172)$, and produced pressure on the part of the workers $(1.1450 \pm 0.9294)$. A study in China observed similar results among their workers who reported that they engaged in repetitious work for prolonged hours reported feeling more exhausted. In contrast, those whose work was not repetitive had lower feelings of depersonalization. ${ }^{17}$ Another study among steel and ironworkers in China observed that when the effort-reward imbalance was high, the indicators led to burnout, such as emotional exhaustion and cynicism. Effort-reward imbalance occurred when the job demands overweigh the compensation received by the employee. ${ }^{18}$

For burnout, the following indices were included in this study of female factory workers: boredom/boring work, repetitious work, fast-paced work, work pressure, not sufficient compensation, work-home conflicts, upskilling, physically tiring, mentally tiring, and salary is not sufficient to meet basic needs.

\section{Boredom}

Boredom at work could be a factor in burnout. Harju and Hakanen (2016) identified types of job boredom among white-collar workers. This was described as work stagnation wherein employees cannot use their full capabilities to perform at work and felt inadequate. ${ }^{19}$ Van Hooff and Van Hooft (2016) showed that those with high work centrality have depressed moods at the end of their shifts and in the evening, especially when they experienced work-related boredom. ${ }^{20}$ Moreover, employees who have high work boredom and low job autonomy have significantly higher frustration levels. ${ }^{21}$ This may be attributed to low job satisfaction, which may lead to burnout which was evident in the study of Kroll et al. (2016). ${ }^{22}$

However, in this study among female factory workers, there was a low average response for 'work is boring' ( 0.259 $\pm .560)$.

\section{Repetitious work}

Repetitious work is a mediating factor to burnout. A study on shipyard workers in Spain showed that burnout was affected by under-stimulation, monotonous and repetitive work that these workers were subjected to. ${ }^{23}$ Similarly, in a study among room attendants, job stress results in burnout through repetitive work tasks. It can also lead to a lower sense of accomplishment to employees, leading to lower morale in their jobs and negative behavior, which could further exacerbate burnout. ${ }^{24}$ This was especially true among copper-nickel miners in China. ${ }^{25}$

In this study among female factory workers, there was a high average response for 'repetitious work' $(1.3172 \pm 0.8905)$.

\section{Fast-Paced Work}

A study among pediatricians showed that females tend always to feel more rushed than their male counterparts. ${ }^{26}$ This was also the same in a study among teachers in Norway and nurses in Japan, wherein it was found that time pressure 
was a significant predictor of emotional exhaustion. ${ }^{27,28}$ Another study showed that time pressure was also positively associated with depersonalization, another component of burnout. ${ }^{28}$ Therefore, it can be claimed that less time pressure in the workplace could result in lower levels of burnout among workers. ${ }^{29}$ In this study among female factory workers, the mean score was $1.0846 \pm 0.9172$, suggesting a moderate perception of fast-paced work. Meanwhile, results also showed that they also experienced low autonomy on rest index $(24.159 \pm 30.788)$.

\section{Work Pressure}

When an employee is subjected to intense pressure, this can result in burnout. ${ }^{30}$ In a study among emergency department physicians, high levels of emotional exhaustion were related to intense work pressure, whereas, among medical staff in the Midwestern United States, heavy work pressure was positively associated with burnout. ${ }^{31,32}$ In a study by Van der Heijden, Mahoney, and Xu (2019) among nurses, work pressure, was categorized under perceived effort and had a direct effect on burnout and a negative relationship with turnover intention. ${ }^{33}$

Therefore, when an employee was subjected to intense work pressure, this could result in burnout and eventual resignation of the employee if not addressed appropriately. In this study among female factory workers, there was a considerable number reporting work pressure (1.145 \pm 0.9294).

\section{Work is not proportional to salary}

The workload is one risk factor of burnout. This was evidenced in a study among workers of the manufacturing industry in Indonesia that high workload had an effect on burnout. ${ }^{34}$ Similarly, high job demands increased burnout and depressive symptoms for workers while also negatively associated with life satisfaction. ${ }^{35}$ This can lead to poor health outcomes in the long run. ${ }^{36}$

When the workload is not proportional to salary in general, motivation at work is low. ${ }^{37}$ Inadequate salary was also a significant determinant of low job satisfaction. ${ }^{38}$

Many respondents reported that salary was not proportional to workload $(0.6526 \pm 0.8617)$. Meanwhile, results also showed that they experienced low autonomy health, safety, and compensation index $(8.891 \pm 8.524)$ and low training index $(29.582 \pm 12.632)$.

\section{Conflict of priorities between work and family}

Burnout could be influenced by work and personal life conflicts. A study among males and females showed that burnout was positively associated with work-to-family conflicts. ${ }^{39}$ Among working women, Gupta \& Srivastava (2020) showed that burnout was positively associated with work-life conflict, and similarly, the latter was negatively associated with family support. ${ }^{40}$ The same was also evident among female pediatricians that showed women were less likely to be successful in balancing their job and other personal responsibilities in life). ${ }^{39}$ This may be due to multiple responsibilities and more non-work-related responsibilities handled by females. For example, among pediatricians, results showed that women have more household responsibilities than men. These responsibilities are coordinating schedules, doing laundry, grocery shopping, cooking and cleaning, caring for pets, and more responsibility for caring for their children.

Moreover, more females were less satisfied with their share of home responsibilities. ${ }^{26}$ The lack of support from their spouses in terms of household responsibilities can further contribute to the mental stress of females, which can result in much higher levels of personal burnout among working women. ${ }^{39,40}$

In this study among female factory workers, there was a considerable number reporting conflict between work and family $(0.7039 \pm 0.8581)$.

\section{Requires upskilling regularly}

Upskilling employees results in better job satisfaction which then results in lower levels of burnout. In a study, those with higher training adequacy or upskilling have a lowaverage range of exhaustion. ${ }^{41}$ Similarly, high-performance work systems, which is a platform for increased employee engagement, performance, motivation, and knowledge and skills, were associated with employee well-being and engagement among call center workers in India. ${ }^{42}$ This can result in higher job satisfaction and attention and, consequently, negate burnout among employees. One of the characteristics of meaningful tasks was new skills that can subsequently influence employees' growth and learning while increasing their job engagement by being challenged. ${ }^{43}$

However, in our study among female factory workers, upskilling was perceived negatively. This may be due to more work demands arising from constant training and upskilling. In this study among female factory workers, the highest mean response was for the item "work requires new skills or upskilling regularly" at $1.619 \pm .762$, suggesting that most respondents were required to upskill regularly. Furthermore, the skilled work content index was high at an average of $70.801 \pm 22.87$.

\section{Physically and Mentally Tiring}

High work demands, in general, affect the feeling of burnout. In a study among workers in Germany, it was found that employees with higher cognitive demands in terms of work were more susceptible to feeling fatigued. More so, doing unlearned things sometimes or frequently has been associated with $10.6 \%$ of feeling fatigued during their shifts. ${ }^{44}$ Gauche, de Beer, and Brink (2017) showed that employees viewed high cognitive demands as a risk factor for burnout. ${ }^{16}$ On the other hand, physically tiring jobs were associated with fatigue among the general working population in Denmark. Physical exposures in the said study were defined as working with bent/twisted back, repetitive arm movement, 
standing in the same place, arms at or above shoulder height, squatting or kneeling, lifting/carrying, or pushing/pulling. Therefore, an increased number of exposures to these physical risk factors could increase work-related fatigue among younger and older workers. ${ }^{45}$

In this study, many respondents reported physically and mentally tiring work $(0.9668 \pm 0.8887)$.

\section{Salary not enough to meet workers' needs}

Compensation is a motivating factor among employees. When it is inadequate, this can result in job dissatisfaction and eventual burnout of workers because salary was a motivational factor among employees that could influence job satisfaction among workers. ${ }^{38,46,47}$ Job dissatisfaction influences employee burnout. More so, Khosravi et al. (2017) showed that low salary affected emotional exhaustion and burnout among primary healthcare providers. ${ }^{14}$

In this study among female factory workers, "Salary is not enough to meet worker's needs" also has a high average response, suggesting that most respondents felt that their salary was insufficient to sustain their daily needs.

\section{Positive Working Arrangements}

Burnout arises from a negative working environment. There is a need to promote a positive work environment and a better organizational climate. A positive working environment contributes to the better well-being of employees and mitigates burnout. Badrianto and Ekhsan (2020) showed that both working environment and job satisfaction significantly positively affect employee performance. ${ }^{48,49}$ Likewise, pay or compensation was a motivational factor as employees were satisfied when they were recognized and compensated appropriately. ${ }^{46}$

The organizational climate factors were also looked into in this study among female factory workers. Beyond personal factors that could influence an individual's level of burnout, environmental factors also contributed to this occurrence. ${ }^{18}$ In this study, the nature of the management of female factory workers was explored. Results revealed that supportive measures for employees were low and inconsistent. This included Health and Safety Policies, seminar and training participation, compensation, insurance, and protection from harassment and discrimination. The presence of a robust organizational support system does not only improve the prevention of burnout but also contributed to a safer work environment. ${ }^{12,50}$

A study in Korea found that the more accidents and workload an employee experiences, the higher the perceived anxiety regarding the safety of the work environment. However, they found that leadership and climates that promote safety were protective factors against the risk perception of the employees. The majority of the variance observed in risk perception came from the environmental factors of the workplace, including the leadership and organization, which was similarly reported in other studies. ${ }^{8,18}$
The workplace environment becomes even more concerning when seen from the female perspective. In this study, the female respondents also reported that their job sometimes required severe mental concentration, which added more pressure and effort to the worker's end. Moreover, they have also reported frequently experiencing hazard exposures. Employed females also tended to have to juggle work responsibilities with house and family responsibilities. In addition to contributing to the household's income, they were also socially expected to maintain the structure and organization of the home. This can contribute to their overall daily demands and could lead to further exhaustion. In a study among female garment workers whose tasks also involved long hours of repetitious work, the researchers observed highstress levels. Moreover, they complained that their work was demanding, affecting their health and keeping them away from their children and families. ${ }^{5}$

\section{CONCLUSION}

This study has so far come up with indices of burnout unique to female factory workers. The indexes are boredom/ boring work, repetitious tasks, fast-paced work, work pressure, not sufficient compensation, work-home conflicts, upskilling, physically tiring, mentally tiring, and salary is not sufficient to meet basic needs. With Cronbach alpha, these indices were shown to have high scale reliability and internal consistency. Using nine indices, the total burnout score was measured.

This study has also come up with the indexes of organizational climate relating to job autonomy, content of job, and nature of management. The several items under each of these components were subjected to Factor Analysis to come up with indexes of organizational climate, namely, Autonomy on Quality Index, Autonomy on Rest Index, Skilled work content Index, Physical work content Index, Hazardous work content Index, Health, Safety, and Compensation Index, and Training Index. This study came up with a burnout index unique to the Filipino factory worker, not just based on subjective expert opinion, but datadriven and statistically derived.

Future studies can explore the relationship between burnout scores developed here as the endogenous and organizational climate indices as the exogenous variables.

\section{Statement of Authorship}

The author contributed in the conceptualization of work, acquisition and analysis of data, drafting and revising, and approved the final version to be published.

\section{Author Disclosure}

The author declared no conflicts of interest.

\section{Funding Source}

None. 


\section{REFERENCES}

1. The World Bank. The World Bank in the Philippines [Internet]. World Bank. 2016 [cited 2021 Apr]. Available from: https://www.worldbank. org/en/country/philippines/overview.

2. Huang WL, Guo YL, Chen PC, Wang J, Chu PC. Association between Emotional Symptoms and Job Demands in an Asian Electronics Factory. Int J Environ Res Public Health. 2017 Sep;14(9):1085.

3. Sharma L, Srivastava M. A Scale to Measure Organizational Stress among Women Workers in the Garment Industry. Eur J Train Dev. 2020. Epub 2020 May 4.

4. Tran BX, Vu GT, Pham KTH, Vuong QH, Ho MT, Vuong TT, et al. Depressive Symptoms among Industrial Workers in Vietnam and Correlated Factors: A Multi-Site Survey. Int J Environ Res Public Health. 2019 May;16(9):1642.

5. Akhter S, Rutherford S, Feroza AK, Bromwich D, Anwar I, Rahman A, et al. Work, gender roles, and health: Neglected Mental Health Issues Among Female Workers Ready-made Garment Industry in Bangladesh. Int J Womens Health. 2017; 9: 571-579.

6. Serrano, AC. Coping with Work-related Stress among Factory Workers in the Manufacturing Industry. Int J Bus Marketing and Management. 2019; 4(12): 37-45.

7. Seo Y, Chung SW. Abusive Supervision, Psychological Capital, and Turnover Intention: Evidence from Factory Workers in China/ Supervisión Abusiva, Capital Psicológico e Intención de dejar el Empleo: Estudio de la Situación de Trabajadores de Fábrica en China. Relations industrielles/Industrial Relations. 2019; 74(2): 377-404.

8. Gibbs A, Jewkes R, Willan S, Al Mamun M, Parvin K, Yu M, et al. Workplace Violence in Bangladesh's Garment Industry. Soc Sci Med. 2019 Aug;235:112383.

9. Venketash. Organisational Climate: Meaning, Characteristics, and Factors [Internet]. N.D. [cited 2021 May]. Available from: https:// www.yourarticlelibrary.com/organization/organisational-climatemeaning-characteristics-and-factors/53226

10. Lubrańska A. [Organizational climate and burnout syndrome]. Klimat organizacyjny a doświadczanie wypalenia zawodowego. Med Pr. 2011;62(6):623-31. Polish.

11. World Health Organization. Burn-out an "occupational phenomenon": International Classification of Diseases. Geneva: World Health Organization; c2021 [updated 2019 May 28; cited 2021 May]. Available from: https://www.who.int/news/item/28-05-2019-burnout-an-occupational-phenomenon-international-classification-ofdiseases

12. Heinemann LV, Heinemann T. Burnout Research: Emergence and Scientific Investigation of a Contested Diagnosis. SAGE Open. 2017 Jan-Mar;7(1):1-12.

13. Herminingsih A, Kurniasih A. The Influence of Workload Perceptions and Human Resource Management Practices on Employees' Burnout (A Case Study on Mercu Buana University Administrative Staffs). Eur J Manag Bus Econ. 2018;10(21):19-26.

14. Johnston M. Secondary Data Analysis: A Method of which the Time Has Come. Qualitative and Quantitative Methods in Libraries (QQML). 2014 Sep;3(3):619-26.

15. Van den Broeck A, Elst TV, Baillien E, Sercu M, Schouteden M, De Witte H, Godderis L. Job Demands, Job Resources, Burnout, Work Engagement, and Their Relationships: An Analysis Across Sectors. J Occup Environ Med. 2017 Apr;59(4):369-76.

16. Gauche C, de Beer LT, Brink L. Exploring demands from the perspective of employees identified as being at risk of burnout. Int J Qual Stud Health Well-being. 2017 Dec;12(1):1361783. PubMed PMID: 28784048.

17. Luo H, Yang H, Xu X, Yun L, Chen R, Chen Y, et al. Relationship between Occupational Stress and Job Burnout among Rural-to-urban Migrant Workers in Dongguan, China: A Cross-sectional Study. BMJ Open. 2016; 6(8).

18. Guo H, Guo H, Yang Y, Sun B. Internal and External Factors Related to Burnout among Iron and Steel Workers: A Cross-sectional Study in Anshan, China. PloS One. 2015; 10(11).

19. Harju LK, Hakanen JJ. An Employee Who Was Not There: A Study of Job Boredom in White-collar Work. Pers Rev. 2016;42(2):374-91.
20. Van Hooff MLM, van Hooft EAJ. Work-related Boredom and Depressed Mood from A Daily Perspective: The Moderating Roles of Work Centrality and Need Satisfaction. Work Stress. 2016;30(3): 209-27.

21. Van Hooft EAJ, van Hooff, MLM. The State of Boredom: Frustrating Or Depressing? Motiv Emot. 2018 Jul;42:931-46.

22. Kroll H, Macaulay T, Jesse M. A Preliminary Survey Examining Predictors of Burnout in Pain Medicine Physicians in the United States. Pain Physician. 2016;19:E689-96.

23. Reig-Botella A, Detaille S, Clemente M, Lopez-Golpe J, de Lage A. Time Perspective and the Risk of Developing Burnout: An Empirical Study among Different Blue-Collar Workers in Spain. Sustainability. 2021; Mar 16;13:3271.

24. Chiang CF, Liu BZ. Examining Job Stress and Burnout of Hotel Room Attendants: Internal Marketing and Organizational Commitment as Moderators. J Hum Resour Hosp Tour. 2017 Jan;16(4):367-83.

25. Sun X, Li Z, Chen Z, Liu J, Ge H. The Status of Job Burnout and Its Influence on The Working Ability of Copper-nickel Miners in Xinjiang, China. BMC Public Health. 2020 Mar;20(1):305.

26. Starmer AJ, Frinter MP, Matos K, Somberg C, Freed G, Byrne BJ. Gender Discrepancies Related to Pediatrician Work-Life Balance and Household Responsibilities. Pediatrics. 2019;144(4):e20182926. PubMed PMID: 31506304.

27. Skaalvik EM, Skaalvik S. Dimensions of Teacher Burnout: Relations with Potential Stressors at School. Soc Psychol Educ. 2017 Aug 12;20:775-90.

28. Cao X, Naruse T. Effect of Time Pressure on The Burnout of Homevisiting Nurses: The Moderating Role of Relational Coordination with Nursing Managers. Jpn J Nurs Sci. 2019;16:221-31.

29. Linzer M, Harwood E. Gendered Expectations: Do They Contribute to High Burnout Among Female Physicians? J Gen Intern Med. 2018 Feb;33:963-5.

30. Yang X. Correlation between Mental Health, Work Pressure and Job Burnout of Music Teachers. Rev Argentina de Clin Psicol. 2020;29:542-9.

31. Hamdan M, Hamra AA. Burnout among Workers in Emergency Departments in Palestinian Hospitals: Prevalence and Associated Factors. BMC Health Serv Res. 2017 Jun;17:407.

32. Grace MK, VanHeuvelen JS. Occupational Variation in Burnout among Medical Staff: Evidence for The Stress of Higher Status. Soc Sci Med. 2019 Jul;232:199-208.

33. Van der Heijden B, Mahoney CB, Xu Y. Impact of Job Demands and Resourced on Nurses' Burnout and Occupational Turnover Intention Towards an Age-Moderated Mediation Model for the Nursing Profession. Int J Environ Res Public Health. 2019 Jun;16:2011.

34. Soelton M, Hardianti D. Factors Affecting Burnout in Manufacturing Industries. In: Proceedings of 4th International Conference on Management, Economics and Business; 2019 Jun 26-27; Jakarta, Indonesia. Paris: Atlantis Press; 2020. p. 56-52.

35. Upadyaya K, Vartiainen M, Salmera-Aro K. From Job Demands and Resources to Work Engagement, Burnout, Life Satisfaction, Depressive Symptoms, and Occupational Health. Burn Res. 2016 Dec;3(4):101-8.

36. Rosella LC, Fu L, Buajitti E, Goel V. Death and Chronic Disease Risk Associated with Poor Life Satisfaction: A Population-Based Cohort Study. Am J Epidemiol. 2019 Feb;188(2):323-31.

37. Deghan A, Hosseini SA, Rassfiani M, Dalvand H. Exploring Perceptions of Health Caregivers on the Causes of Caregivers' Occupational Burnout in Institutes of Children with Cerebral Palsy: A Qualitative Study. Electron Physician. 2017 Jun;9(6):4516-23.

38. Afshar HS, Doosti M. An Investigation into Factors Contributing to Iranian Secondary School English Teachers' Job Satisfaction and Dissatisfaction. Res Pap Educ. 2016;31(3):274-98.

39. Huang SL, Li RH, Fang SY, Tang FC. Well-Being: Its Relationship with Work-to-Family Conflict and Burnout among Males and Females. Int J Env Res Pub He. 2019 Jun 28;16:2291.

40. Gupta P, Srivastava S. Work-life Conflict and Burnout among Working Women: A Mediated Moderated Model of Support and Resilience. Int J Organ Anal. 2020 Jul 27;1-27.

41. Mcmillan K, Butow P, Turner J, Yates P, White K, Lambert S, et al. Burnout and the Provision of Psychosocial Care amongst Australian Cancer Nurses. Eur J Oncol Nurs. 2016 Jun;22:37-45. 
42. Ananthram S, Xerri MJ, Teo STT, Connell J. High-performance Work Systems and Employee Outcomes in Indian Call Centres: A Mediation Approach. Pers Rev. 2018 May;47(4):931-60.

43. Sonnentag S. A Task-level Perspective on Work Engagement: A New Approach That Helps to Differentiate the Concepts of Engagement and Burnout. Burn Res. 2017 Jun;5:12-20.

44. Meyer SC, Hünefeld L. Challenging Cognitive Demands at Work, Related Working Conditions, and Employee Well-Being. Int J Environ Res Public Health. 2018 Dec;15:2911.

45. Bláfoss R, Sundstrup E, Jakobsen MD, Brandt M, Bay H, Andersen LL. Physical workload and bodily fatigue after work: cross-sectional study among 5000 workers. Eur J Public Health. 2019 Apr;29(5): $837-42$.

46. Hee OC, Yan LH, Rizal AM, Kowang TO, Fei GC. Factors Influencing Employee Job Satisfaction: A Conceptual Analysis. Int J Acad Res Bus Soc Sci. 2018 Jun;8(6):331-40.
47. Khosravi A, Ranjbar M, Erfan A, Sadeghi Z, Khojasteh L, Amiri M. Burnout in Primary Health Care Providers in Mazandaran Province. IJHS. 2017;3(4):25-29.

48. Badrianto Y, Ekhsan M. Effect of Work Environment and Job Satisfaction on Employee Performance in PT. Nesiknak Industries. JOBMA. 020 Mar;2(1):85-91.

49. Gabriel KP, Aguinis H. How to Prevent and Combat Employee Burnout and Create Healthier Workplaces During Crises and Beyond. Bus Horiz. 2021. PDF 2021 Feb 4.

50. Oah S, Na R, Moon K. The Influence of Safety Climate, Safety Leadership, Workload, and Accident Experiences on Risk Perception: A Study of Korean Manufacturing Workers. Saf health at work. 2018; 9(4): 427-433.

\section{APPENDICES}

Appendix 1. K-Means Cluster Analysis for Classification of Low, Moderate and High Burnout

\begin{tabular}{lccc}
\hline \multicolumn{1}{c}{ Index of Burnout } & Low range & Moderate range & High range \\
\hline Burnout Score & 0 to 5 & 6 to 10 & 11 to 18 \\
Autonomy on Quality & 0 to 35.99 & 36 to 70.99 & 71 to 100 \\
Autonomy on Rest & 0 to 22.99 & 23 to 62.99 & 63 to 100 \\
Skilled Work Content & 0 to 36.99 & 37 to 65.99 & 66 to 100 \\
Physical Work Content & 0 to 29.99 & 30 to 63.99 & 64 to 100 \\
Hazardous Work Content & 0 to 31.99 & 32 to 68.99 & 69 to 100 \\
Health Safety and Compensation & 0 to 9.9 & 9.91 to 30.99 & 31 to 100 \\
Upskilling and Training & 0 to 39.99 & 40 to 62.99 & 63 to 100 \\
\hline
\end{tabular}

Normal P-P Plot of Regression Standardized Residual

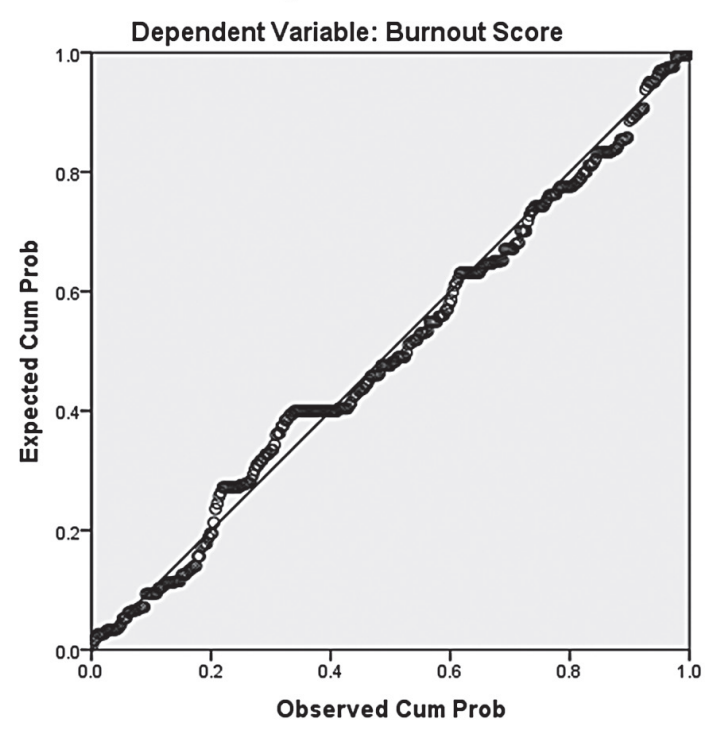

Appendix 2. Burnout Score P-P Plot of Regression.

The Acta Medica Philippina is now accepting original scientific papers, review articles and case reports for its upcoming issues. Please follow the format for submission as indicated in the "Instructions to Authors" elsewhere in the journal.

All papers received shall be properly acknowledged. For inquiries and submission of proposals, please email us at actamedicaphilippina.upm@up.edu.ph 